\title{
Controlling of Solar Photovoltaic Inverters in Different Modes
}

\author{
Muna Hameed Khalaf ${ }^{1}$, Ch. Punya Sekhar ${ }^{2}$ \\ ${ }^{1}$ PG Scholar, Dept. of EEE, University College of Engineering \& Technology, Acharya Nagarjuna University, Guntur, 522510, Andhra \\ Pradesh, India. \\ ${ }^{2}$ Assistans Professor, Dept. of EEE, University College of Engineering \& Technology, Acharya Nagarjuna University, Guntur, 522510, \\ Andhra Pradesh, India
}

\begin{abstract}
The growing penetrate stage of photovoltaic $(\mathrm{PV})$ power generation in low voltage $(\mathrm{LV})$ networks result in voltage rise issues, mainly at the end of the feeders. In order to moderate this trouble, quite a few strategies, such as grid support, transformer tap change, demand-side administration, lively power reduction, and reactive power optimization methods, show their contribution to voltage hold, yet still incomplete. This paper proposes a corresponding volt-for control design between the LV sharing transformer and solar inverters to optimize the PV power penetration level in anagent $L V$ network in Bornholm Island using a multi mode. The approach is to increase the reactive power donation of the inverters nearby to the transformer during overvoltage situation. From the simulation of the circuit, we achieved an improvement in the power constantly.
\end{abstract}

Keywords: Photovoltaic power systems, power distribution, reactive power control, voltage control, for control.

\section{Introduction}

Investments in solar photovoltaic (PV) energy are quicklygrowing worldwide. A gridconnected solar PV system consists of a PV generator that produce electricity from sunlight and power converters for energy withdrawal and grid border control. The smallest unit of a PV generator is a solar cell and a large PV generator is built by many solar cells that are connected together through certain series and parallel connections. Although in most power-generating systems, the main source of energy (the fuel) can manipulate, this is not true for solar energies.Industry must beat a number of industrial issues to deliver renewable energy in significant quantities. Transmission system operators (TSO) observe with great concern the huge growth of multi-MW PV plants. In this context, new grid codes deal with this topic and they are including new criteria in order to make it easy to TSO to properly react against dangerous irradiance fluctuations, i.e., fluctuations under 10 minutes time scale. This risk is especially dangerous in high PV penetration places such as islands (for example, Puerto Rico). It is precisely in islands where new grid codes [1] are becoming more restrictive and they are limiting the maximum fluctuations during a period of time, typically 10 minutes. In addition, other network operators are also working in new grid codes which take the fluctuation problems into account [3]. As a result, energy storage systems (ESS) are necessary to comply with the regulations. Even though the decreasing cost of power electronics devices as well as the breakthrough of new technologies in the field of energy storage [4]-[7] have facilitated the incorporation of ESS into renewable power systems[2], their cost per power unit is a strong function of their capacity, and a too high cost is almost prohibitive for becoming commercially accepted. It In, this way, a method for optimizing the size and operation (losses, lifecycle...) of such ESS in order to meet both application constraints and increase the economic viability of the PV system with an ESS incorporated is essential. There are different ways of using the ESS which allow to achieve the two latter objectives depending on the smoothing control strategy implemented. Likewise, it is logical to think that the control strategy selected in order to smooth out fluctuations will be a crucial decision and storage requirements will depend on the strategy chosen. In this work, the different strategies available in the literature have been evaluated over 1-year 5 seconds power measurements which were recorded in the output of $500 \mathrm{~kW}$ inverter at the $38.5 \mathrm{MW}$ Amareleja (Portugal) PV plant for a maximum allowable ramp-rate value (rMAX) of $2 \% / \mathrm{min}$.

\section{Var Regulation}

Nearly all power system loads require a combination of real power (watts) and reactive power (VARs). Real power must be supplied by a remote generator while reactive power can be supplied either by a remote generator or a local VAR supply, such as a capacitor. Delivery of reactive power from a remote VAR supply result in an additional feeder voltage drop and losses due to increased current flow, so utilities prefer to deliver reactive power from a local source. Since demand for reactive power is higher during heavy load conditions than light load conditions, [5]VAR supply on a distribution feeder is regulated or controlled by switching capacitors on during periods of high demand and off during periods of low demand. As with voltage control, there are both feeder design considerations (to minimize capital costs) and operating considerations.

Supplying VARs when and where demanded is inherent to operate an electric power system. But the flow of reactive power affects power system voltages just as the flow of real power does. The effects of real power flow nearly always have negative effects on voltage while the effects of reactive power flows are sometimes positive and sometimes negative. Experience has proven that overall costs and performance of operating a power system can be better 


\section{International Journal of Science and Research (IJSR) \\ ISSN (Online): 2319-7064}

Index Copernicus Value (2013): 6.14 | Impact Factor (2015): 6.391

managed if voltage control and reactive power control are well integrated.

Fig(1) shows the Var control of photovoltaicConverter control thinks. The control method indicates a comparison of reference and measured values.And finally we have to produce the controlled pulses for converter circuit.

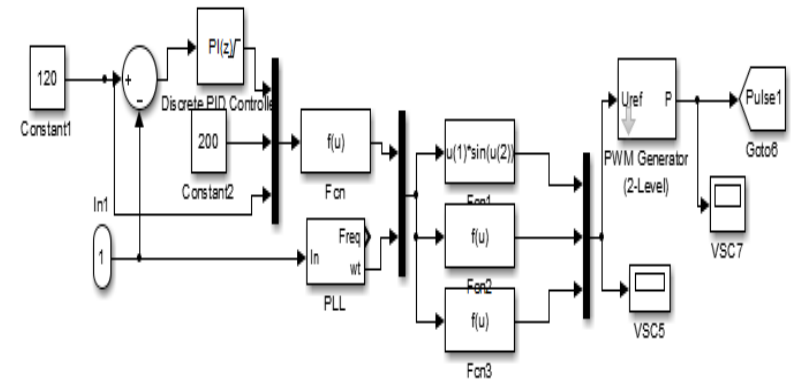

Figure 1: Var Control of PV converter.

\section{Operation Modes of a PV Generator}

The PV generator bus is modelled through one of three models depending on the control mode of the converter. Three control modes are considered.

\section{Power Factor (PF) Control}

The PF control of the converter is enabled, i.e. the converter operates at a constant power factor. The used bus model is PQ type, i.e. the injected P (Pg ) and injected Q (Qg ) are specified.

$$
\frac{P_{g}}{\sqrt{P_{g}^{2}+Q_{g}^{2}}}=\cos \theta
$$

where $\cos \theta$ is the set $\mathrm{PF}$..

This operation mode has two constraints: the rated MVA of the converter may not be violated, and the PF should be maintained constant.

\section{Voltage Control}

The voltage control of the converter is enabled; that means, the converter operates at variable power factor operation. The used bus model is PV type, i.e. the injected P and the voltage magnitude are specified. This operation mode allows the generator to support the voltage profile in the network through injecting reactive power. Voltage control can be done locally, i.e. the reactive power output of the generator is controlled to achieve the specified local voltage at its terminal. The active power output is constant for the dispatch.

\section{Droop Voltage Control}

For this control mode the voltage is controlled according to a specified droop (e.g. Droop $=2 \%$ ) and set the voltage. The droop is defined as:

$$
\text { droop } \%=\frac{\Delta V / V_{n}}{\Delta Q / Q_{n}} \times 100
$$

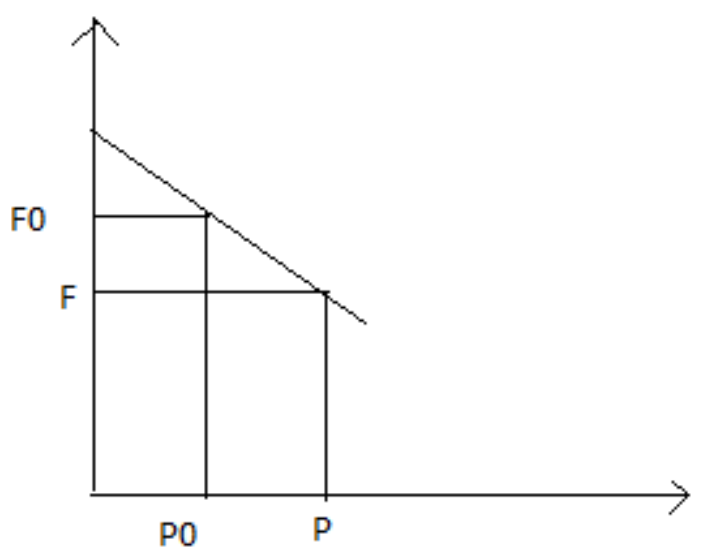

Frequency droop characteristic

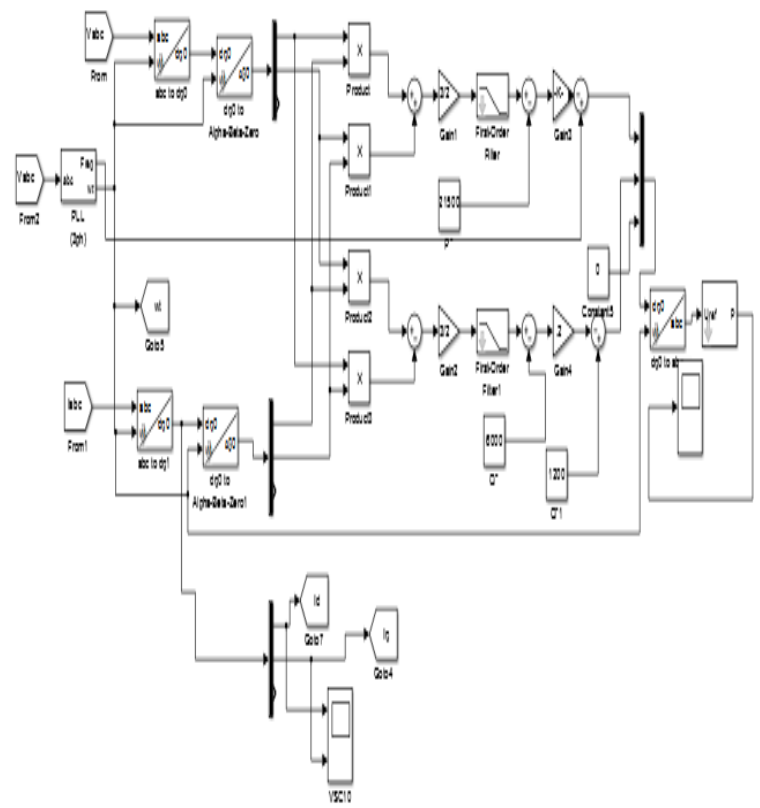

Figure 2: Droop control for solar converter

The generation bus model for this mode is DV type, which is new for power flow calculations (i.e. Not included in the conventional power flow). The generator can be set to control the local voltage at its terminal to a specified set point. With droop control the set point is not reached in any case because the set point is moved (by DV droop) as more reactive power is needed to reach the original voltage set point of the PV generator. The advantage of the droop control is that more than one machine at one bus could control the voltage as well as the participation of the single machine could be configured with the setting of the droop value. When set to voltage control, a droop value can be entered. The voltage on the local bus is then controlled according to the following equations

$$
\begin{aligned}
& V=V_{\text {setpoint }}-d V_{\text {drop }} \\
& d V_{\text {drop }}=\frac{Q-Q_{\text {setoint }}}{Q_{\text {drop }}} \\
& Q_{\text {droop }}=\frac{S_{\text {norm }} \times 100}{\text { droop }}
\end{aligned}
$$

Where 


\section{International Journal of Science and Research (IJSR) \\ ISSN (Online): 2319-7064 \\ Index Copernicus Value (2013): 6.14 | Impact Factor (2015): 6.391}

$\mathrm{V}$ is the actual voltage value of the terminal bus bar.

$\mathrm{V}$ (setpoint) is the specified voltage set point of the PV generator.

$\mathrm{Q}$ is the actual reactive power output of the PV generator.

$\mathrm{Q}$ (set point) is the specified dispatch reactive power of the $\mathrm{PV}$ generator.

Norm $\mathrm{S}$ is the nominal apparent power. Droop is the droop value specified in percentage.

\section{Ramp-rate control}

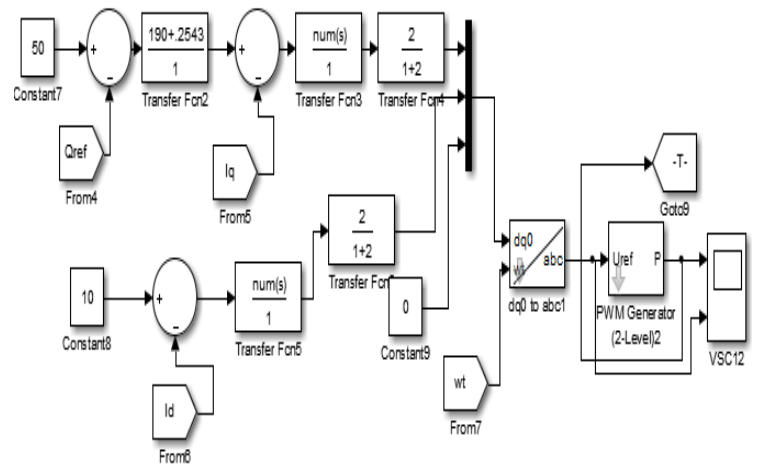

Figure 3: Ramp Rate control for solar converter

Let us consider a maximum permissible ramp rate value of the power injected into the grid, $\operatorname{rMAX}(\% / \mathrm{min})$. Fig. 1 shows a basic model of the corresponding ramp-rate control. Ppvit), Pd (t) and PBAAÍ) are, respectively, the power from the inverter, the power to the grid and the power to the battery.

clearly:

$$
P_{B A T}(t)=P_{G}(t)-P_{P V}(t)
$$

at first, the inverter try to inject all its power into the grid, Poit) - Ppv(t). The control is activated when the greatestacceptable ramp condition is broken.

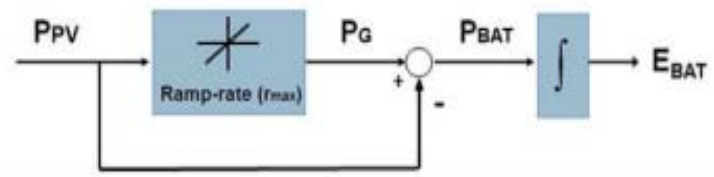

Figure 4: Ramp-rate control model for a given Ppy (t) time series. Looking for simplicity, battery and associate electronic converter losses are ignored.

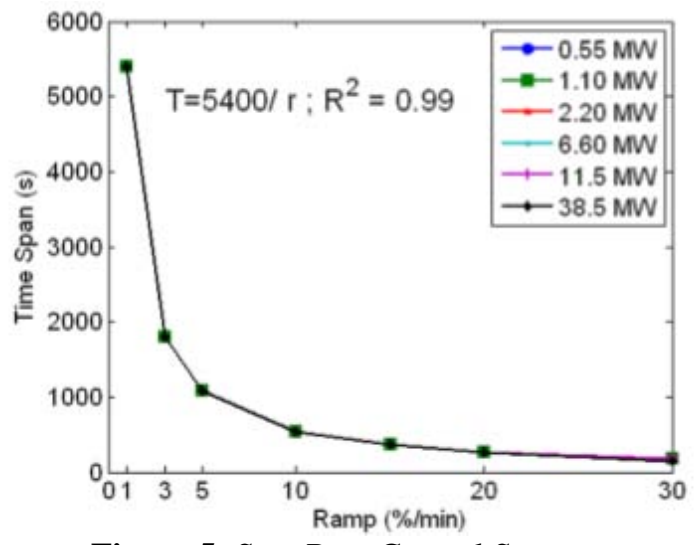

Figure 5: Step Rate Control Strategy
The rate of change in instantaneous output from a power plant. The ramp rate is established to prevent undesirable effects due to rapid changes in loading or discharge.[2]

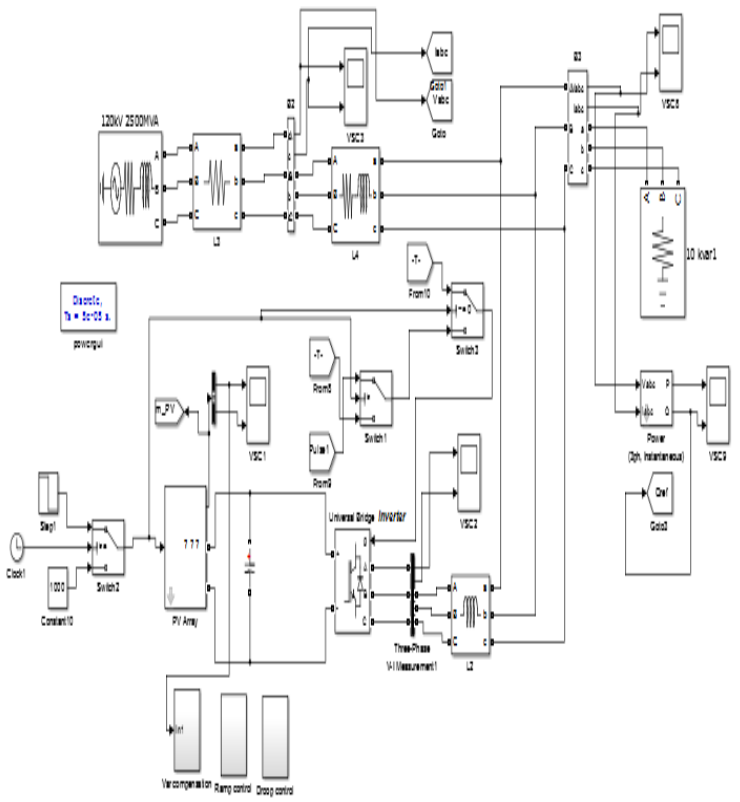

Figure 6: model of controlling of solar photovoltaic inverters.

\section{Simulations Results:}

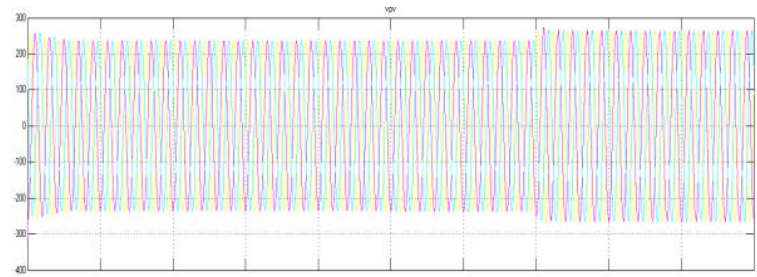

Figure 6: (a) Grid voltage.

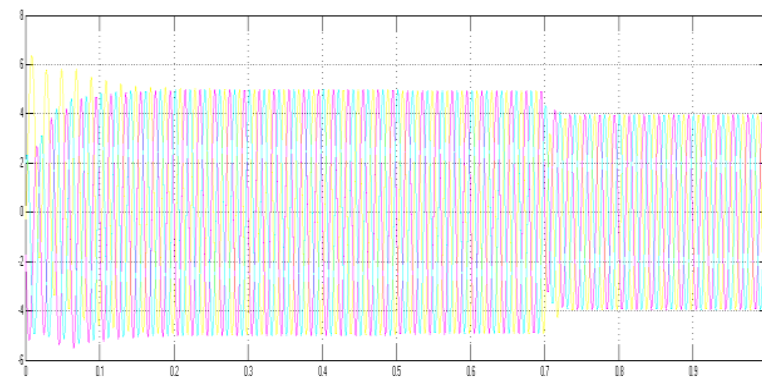

Figure 6: (b) Grid Current.

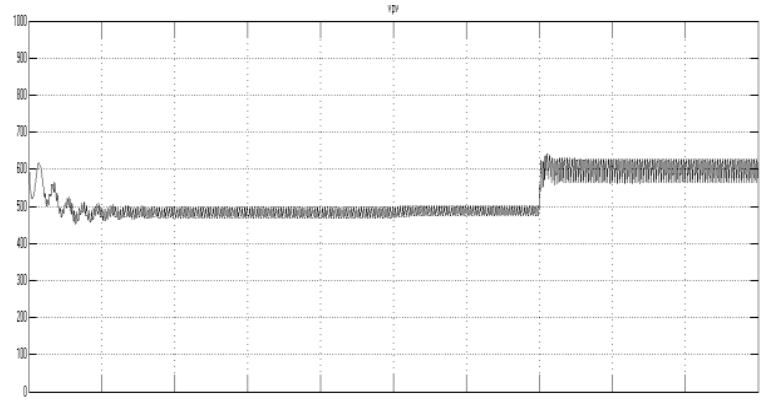

Figure 7: (a) Output Real power 


\section{International Journal of Science and Research (IJSR) \\ ISSN (Online): 2319-7064}

Index Copernicus Value (2013): 6.14 | Impact Factor (2015): 6.391

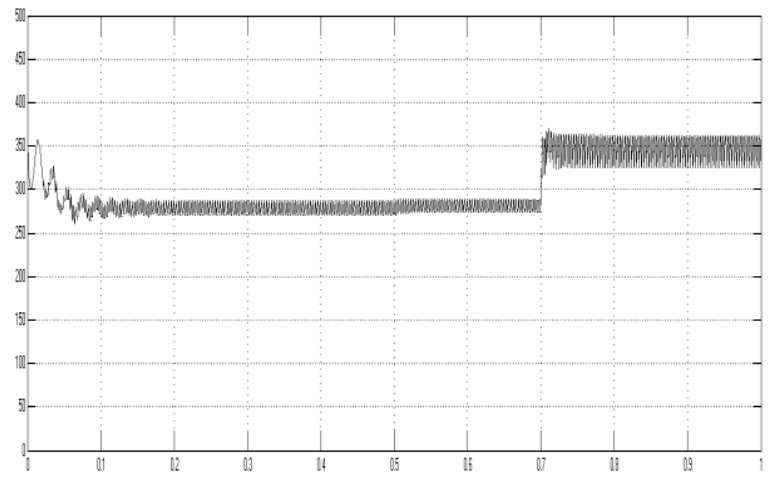

Figure 7: (b) Output Reactive power

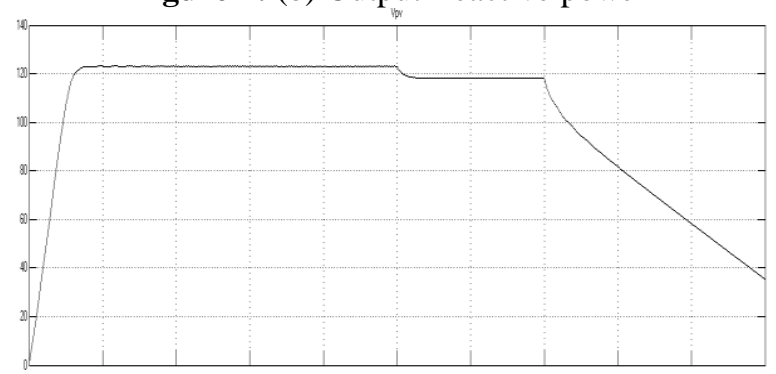

Figure 8: (a) PV voltage, $\mathrm{Vpv}$

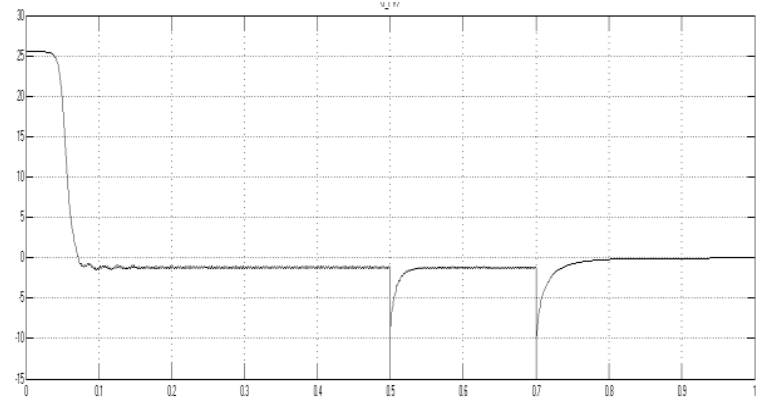

Figure 8: (b) PV current, Ipv

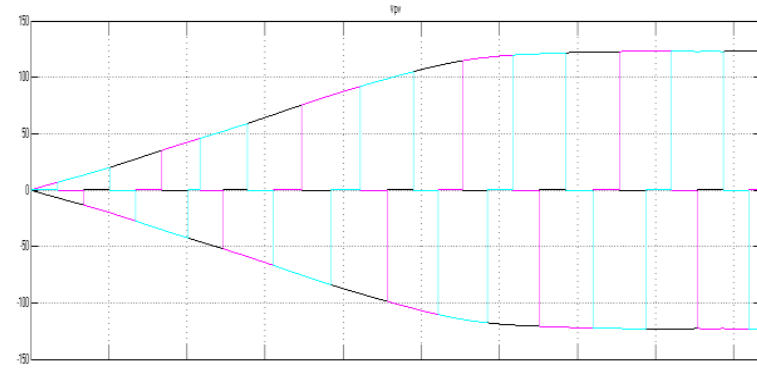

Figure 9: (a)Injected voltage

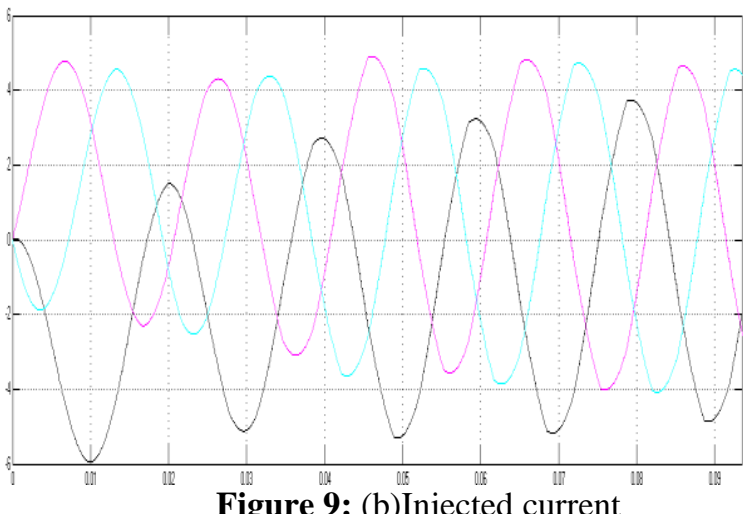

\section{Conclusion}

A Multimode control strategy is used in this paper, this control technique is used to share the real and reactive power to the grid. The control method of droop control is presented in this paper to withstand the active power frequency.

The challenge is to include generation and load dynamics, with their controls, and guarantee stability of islanded microgrids. The simulation results verify the correctness and feasibility of the proposed control strategy.

\section{References}

[1] T. D. Hand, S. Gonzalez, and K. Barrett, "Grid-Tied PV system energy smoothing," in Photovoltaic Specialists Conference (PVSC), Honolulu, HI, USA, 20-25 Jun., 2010, pp. 2762-2766

[2] N. Kakimoto, H. Satoh, S. Takayama, and K. Nakamura, "Ramp-Rate Control of Photovoltaic Generator With Electric Double-Layer Capacitor," IEEE Transactions on Energy Conversion vol. 24, pp. 465473, 2009

[3] M.J. Erickson, T.M. Jahns, and R.H. Lasseter. Comparison of PV inverter controller configurations for CERTS microgrid applications. Energy Conversion Congress and Exposition (ECCE), 2011 IEEE, pages 659-666, Sept. 2011

[4] L. Chen, L. Xiao, Y. Yan, -Circulating Current ${ }^{\text {ee }}$ Characteristics Analysis and the Control Strategy of Parallel System Based on Double Close-loop Controlled VSI", IEEE PESC 2004, pp 4791-4797

[5] A. O. Zue, A. Chandra, Grid Connected Photovoltaic Interface with VAR Compensation and Active Filtering Functions", PEDES 2006,

[6] Huajun. Yu, Junmin. Pan, and An. Xiang, "A multifunction grid connected PV system with reactive power compensation for the grid", Solar Energy, vol. 79, no. 1, pp. 101-106, July. 2005.

[7] R. Neal and R. Bravo, Advanced Volt/VAr control element of Southern California Edison's Irvine smart grid demonstration," in Proc. IEEE Power Syst. Conf. Expo. (PSCE), Phoenix, AZ, USA, Mar. 2011. 